\title{
Exploring the outcomes of BSc Human Biology graduates and their perceptions of the course
}

\author{
Kishvena Sornapooman ${ }^{1}$, Georgina Fyfe ${ }^{1}$ \\ 14855838@student.curtin.edu.au; G.M.fyfe@curtin.edu.au \\ ${ }^{1}$ Curtin University
}

\begin{abstract}
In Australia, the employment outcomes of new graduates are surveyed yearly and evidence of successful employment is linked by some to education quality. Subsequently, higher education providers must ensure their graduates acquire relevant generic attributes as employers seek graduates with 'work ready' skills. Students studying a BSc Human Biology Preclinical degree (HBP) at Curtin University do not have a prescribed profession at graduation, nor do they have fieldwork or clinical practice during their degree to help them confirm their career goals. The Graduate Destination Survey shows that most Curtin HBP graduates are involved in further studies four months post-graduation, but there is little information on what HBP graduates do after completing further studies. Since there is no long-term information on HBP graduate pathways, it is difficult to match valued attributes with career destinations.

This study explores the destinations of Curtin HBP graduates between 2003 and 2012 and their perceptions of the most influential and useful aspects of the course. A mixed-methods approach was used for data collection. Focus group feedback was used to modify an online survey which was distributed to graduates via personal or university emails, or via social media.

The study sample was sorted into graduate profiles based on initial goals, goals formed during their HBP degree and those still without goals at graduation. Most believed the degree itself did not lead directly to satisfactory employment but provided the fundamentals required for further studies. Many graduates were involved in further studies before seeking a career-related job, and most settled into a career four years after graduating from HBP. The study reports the achievements of HBP graduates and recommends strengthening some aspects of the HBP curriculum. It also suggests what information may be most useful to prospective students on whether or not a generic undergraduate degree is a potential pathway to achieving their desired career.
\end{abstract}

Keywords: Graduate destinations, graduate attributes, employment outcomes, generic undergraduate degrees

\section{Introduction}

Governments, industries and the higher education sector recognise the importance of developing graduate attributes of university students (Coates, 2005) and exploring graduate destinations and outcomes. Graduate attributes are the qualities, skills and understandings a university community agrees its students should develop during their time with the institution (Bowden, Hart, King, Trigwell \&Watts, 2000). The Australian labour market recognises the 
importance of a university degree and its accompanying generic attributes (Li \& Miller, 2013). Graduate employment is a key factor for measuring the quality of a degree; hence universities have progressively incorporated the development of graduate attributes into their quality measures (Shah, Cooper \& Burke, 2007). Higher education providers must ensure that their graduates acquire relevant generic attributes (Barrie, 2012) because Australian employers seek graduates with 'work ready' skills and will ask applicants for evidence of graduate attributes (Oliver, Whelan, Hunt \& Hammer, 2011). Graduate destination data informs higher education institutions about employment outcomes of graduates, and provides information on the attributes graduates are expected to possess (or develop gradually) in the early years of employment (Li \& Miller, 2013).

Data on graduate destinations and attributes are captured through the use of questionnaires (Graduate Careers Australia [GCA], 2013). Often, Government and Industry sectors conduct focus groups prior to creating a questionnaire to increase its quality and validity (Britt \& Weingart, 2005). In Australia, validated instruments such as the Graduate Destination Survey (GDS) and Course Experience Questionnaire (CEQ) are used by Government agencies to inform the Higher Education sector about graduate destinations and attributes (GCA, 2013). These questionnaires include closed and/or open-ended questions that generate quantitative and qualitative data (Covell, Sidani \& Ritchie, 2012; Yilmaz, 2013).

Curtin University uses the GDS and CEQ to investigate outcomes and attributes of graduates, providing valuable information on employment prospects and perceptions of graduate attributes (Graduate Careers Australia, 2013). Professional positions of graduates who studied a bachelor of science in Human Biology, referred to as Human Biology Preclinical (HBP) since 2008 were not reported in the 2011 GDS report because the GDS requires a minimum of six responses to report employment positions (GCA, 2013c: Australian Graduate Survey [AGS] 2011).

Both the GDS and CEQ reports capture the activities and perceptions of Curtin students four months after they have graduated (GCA, 2013). However, it may take graduates longer to find relevant graduate positions (Coates \& Edwards, 2009). In America, the 'PhD's 10 years later study' is used, and similarly, the Graduate Longitudinal Study New Zealand collects information, although this is longitudinal information which is not readily available for specific cohorts. Long-term Australian studies such as the Beyond Graduation Survey (BGS) and Graduate Pathways Survey (GPS) gather detailed information on graduate outcomes, but are not institution and course specific, e.g. Human Biology major (Australian Council for Educational Research [ACER], 2008; GCA, 2013a: BGS 2012). In addition, Curtin University was not part of the 2012 BGS, thus there is no long-term data available on Curtin graduates.

The Australian GDS and CEQ respondents are graduates who are often either very new to employment in their profession, or have not yet secured such employment (Oliver et al., 2011). Some graduates may choose to enter jobs that do not require their qualification, as these jobs may simply be part of a career path to higher-level jobs that match their educational attainment (Schomburg, 2007).

The GDS data shows that most Curtin HBP graduates are involved in further studies four months after graduation (GCA, 2013c: AGS 2011), but there is no specific information on what HBP graduates do after completing further studies, so it is difficult to match valued attributes with career destinations. Therefore, data from the CEQ are not always useful in investigating graduate attributes because four months after graduation students may not be in a career for which those attributes are relevant.

Furthermore, employment outcomes can be influenced by several factors external to the curriculum such as extra curricula activities (hobbies, volunteer work or community services); information not captured by the GDS (McInnis, Griffin, James \& Coates, 2001). Additionally, the GDS does not capture information about whether the expectations of new graduates (their own career prospects, or views of their employers) are being met (Oliver et al., 2011)

Sornapooman, K. \& Fyfe, G. (2015). Exploring the outcomes of BSc Human Biology graduates and their perceptions of the course. Journal of Teaching and Learning for Graduate Employability, 6 (1), 24-43. 
and there are several challenges involved in capturing employer feedback, such as building a workable database of employers (Nair \& Mertova, 2009).

Feedback from Curtin students provided by unit-based evaluations during their studies is rich and useful (Tucker, Pegden \& Yorke, 2012), but there is evidence that students do not see the value of some aspects of their course until after they have graduated and have been given the opportunity to apply acquired attributes in the work environment or further study choices (Coates \& Edwards, 2009).

In light of these information gaps for certain cohorts, this study will explore the destinations of HBP graduates who graduated between 2003 and 2012 and will also investigate their perceptions of the most influential and useful aspects of the HBP course.

\section{Method}

Low risk ethical approval was obtained from the university's Human Research Ethics Committee. All participants were provided with an information sheet prior to participation.

\section{Participants}

All participants were graduates from the Human Biology Preclinical (HBP) course at Curtin University between 2003 and 2012. There were a total of 136 graduates contacted using university/personal emails and/or social media with the assistance of key contacts. Graduates were asked to contribute to a focus group and a follow-up online survey.

Focus groups were conducted prior to the online survey. Two focus group methods were employed; a face-to-face (FTF) method and an online asynchronous method.

Face-to-face focus group method

One focus group session and one semi-structured interview were conducted. The focus group session consisted of two female graduates from 2012 and the semi-structured interview consisted of one female graduate from 2005. Both sessions ran for approximately 25 minutes. The investigator facilitated the session by using a prepared script. The following questions were asked:

(1) What were your initial motivations to choose the HBP course?

(2) What were your plans after graduating from HBP?

(3) When you completed the HBP course, how confident were you to take the next step?

(4) What aspects of your university life did you enjoy the most?

(5) What aspects of the course did you enjoy the most?

(6) What aspects of the course did you least enjoy?

(7) If you were to speak to future students of the course, what highlights of the course would you mention?

Follow-up questions were asked to encourage greater feedback from the participants. Sessions were recorded with the iTalk application using an iPad. Audio recordings were transcribed manually before being sent to participants for verification and editing where necessary.

\section{Online asynchronous focus group method}

Guidelines to establish and contribute to a blog-based discussion were sent to participants interested in contributing to the WordPress discussion. Six graduates participated and discussion was conducted and monitored for four weeks. Questions discussed were identical to the FTF focus group questions. 
To test question clarity and understanding and allow the investigator to practice conducting a group, the FTF and online method were piloted with $3^{\text {rd }}$ year HBP students from a semester one class. Transcripts from the pilot focus groups were not analysed and are not reported as results in this study.

\section{Online survey}

An initial survey was constructed prior to the focus groups. Some questions in the initial survey were derived from the Graduate Destination Survey (GDS) and Course Experience Questionnaire (CEQ); surveys that are used annually in Australia to collect information about graduates and have had the validity of the questions tested over the years since its development (Grace, Weaven, Bodey, Ross \& Weaven, 2012). Focus group transcripts were read several times to capture noticeable and frequent themes, which were then used to refine the initial survey. Closed questions recorded respondents' demographic information, employment outcomes and further education since graduating. The following open-ended questions captured the respondents' perceptions of the most useful and influential aspects of the course:

(1) Please give an example of some influential aspects of the HBP degree course that helped you decide on a study/career path?

(2) Were there any key factors external to the HBP degree course that helped you decide on a study/career path?

(3) Please give an example of some key aspects of the HBP degree course that have been most useful in your life since graduating?

(4) What did the HB degree course not provide that would have been helpful for your further study choices or career?

The final survey was created and uploaded using web-based survey software (Qualtrics). Skip and display logic were used to create a survey that was applicable to each respondent. The final survey had 45 questions of which 29 were close-ended and 16 were open-ended.

\section{Statistical analysis}

Survey data were exported into Microsoft Excel and SPSS Statistics 20 to generate descriptive statistics on quantitative responses with selected characteristics and across cohorts.

All focus group transcripts and open-ended responses were exported into Microsoft Excel before being imported into NVivo 10, a qualitative data analysis program, where coding was completed. The focus group transcripts and open-ended survey responses were coded separately initially and then merged into thematic categories. These categories were divided into smaller emergent themes until no further division was possible.

\section{Online survey response}

Of 136 possible HBP graduates from 2003 to 2012, 74 were successfully contacted and asked to participate. Sixty-two graduates could not be contacted by email or social media requests. Three graduates agreed to participate in the FTF focus groups and six contributed to the online asynchronous focus group. In total, 42 of the 74 contacted graduates responded to the survey, giving a response rate of 31 per cent. The sample represented almost a third of all graduates from the last 10 years (Table 1). Participants were also encouraged to act as key contacts to recruit HBP graduates through their own social networks. Only one graduate volunteered to act as a key contact for their cohort (2004). Response rates were high for two cohorts (2004 and 2012); with 54 per cent of respondents from 2004 and 89 per cent from 2012. Response rates for other cohorts ranged from 6 per cent to 30 per cent, and have been aggregated to show trends across cohorts. 
Table 1: Survey Respondents and Selected Characteristics

\begin{tabular}{|c|c|c|c|c|c|c|c|c|c|}
\hline $\begin{array}{c}\text { Year } \\
\text { Graduate } \\
\text { d }\end{array}$ & $\begin{array}{c}{ }^{*} \text { Grads } \\
\text { in } \\
\text { cohort } \\
\text { s (N) }\end{array}$ & $\begin{array}{c}\text { Femal } \\
\text { e } \\
\text { grads } \\
(\%)\end{array}$ & $\begin{array}{l}\text { Male } \\
\text { grad } \\
\text { s (\%) }\end{array}$ & $\begin{array}{l}\text { Grads } \\
\text { contacte } \\
\text { d (N) }\end{array}$ & $\begin{array}{l}\text { Resp } \\
\text { to } \\
\text { surve } \\
y(N)\end{array}$ & $\begin{array}{l}\text { Surve } \\
\text { y resp } \\
(\%)\end{array}$ & $\begin{array}{c}\text { Sample } \\
\text { representatio } \\
\text { n (\%) }\end{array}$ & $\begin{array}{l}\text { Femal } \\
\text { e resp } \\
\text { (\%) }\end{array}$ & $\begin{array}{c}\text { Mal } \\
\text { e } \\
\text { res } \\
p \\
(\%)\end{array}$ \\
\hline 2012 & 18 & 55.0 & 44.0 & 16 & 16 & 100 & 88.8 & 57.0 & 43.0 \\
\hline 2011 & 17 & 65.0 & 35.0 & 14 & 5 & 35.7 & 29.4 & 60.0 & 40.0 \\
\hline 2010 & 15 & 40.0 & 60.0 & 4 & 1 & 25.0 & 6.66 & 0.00 & 100 \\
\hline 2009 & 14 & 72.0 & 28.0 & 8 & 3 & 37.5 & 21.4 & 33.0 & 66.0 \\
\hline 2008 & 17 & 71.0 & 29.0 & 5 & 2 & 40.0 & 11.7 & 100 & 0.00 \\
\hline 2007 & 10 & 50.0 & 50.0 & 4 & 1 & 25.0 & 10.0 & 100 & 0.00 \\
\hline 2006 & 9 & 67.0 & 33.0 & 5 & 1 & 20.0 & 11.1 & 100 & 0.00 \\
\hline 2005 & 7 & 43.0 & 57.0 & 3 & 2 & 66.6 & 28.5 & 100 & 0.00 \\
\hline 2004 & 13 & 85.0 & 15.0 & 10 & 7 & 70.0 & 53.8 & 71.0 & 29.0 \\
\hline 2003 & 16 & 58.0 & 42.0 & 5 & 4 & 80.0 & 25.0 & 100 & 0.00 \\
\hline Total & 136 & & & 74 & 42 & 56.8 & 30.9 & & \\
\hline
\end{tabular}

*Grads $=$ Graduates

The survey respondents were predominantly female (67\%), enrolled full-time (95\%) and attended classes on campus (100 per cent). Most of the graduates were HECS students and deferred some or all of their HECS debt (76.2 per cent). Ninety-five per cent of respondents were Australian citizens or permanent residents and 97.6 per cent indicated that English was their first language. Forty-two per cent of respondents currently lived in the outer metropolitan Perth, while 34.1 per cent lived in the inner metropolitan regions. The remainder lived in remote and rural areas of Western Australia, interstate or overseas. The majority of respondents' highest completed qualification prior to the HBP degree was secondary school (85.7\%).

\section{Results}

\section{Course choice}

Figure 1 shows responses to the question 'Which of the following did you consider when selecting the HBP degree?' Since some of the written responses under 'Other' overlapped with 'Job opportunities in the field' and 'Prepare me for further studies', these were allocated into appropriate categories and new per centages were calculated.

Seventy eight per cent of respondents who had pursued further studies stated that they selected the HBP course to prepare them for further studies in the field, while 12.7 per cent selected the course for job opportunities in that field. The remaining 4 per cent provided open-ended responses stating they had an interest in Human Biology, hence selected the course. Not all students had completed their studies at the time of the survey. 


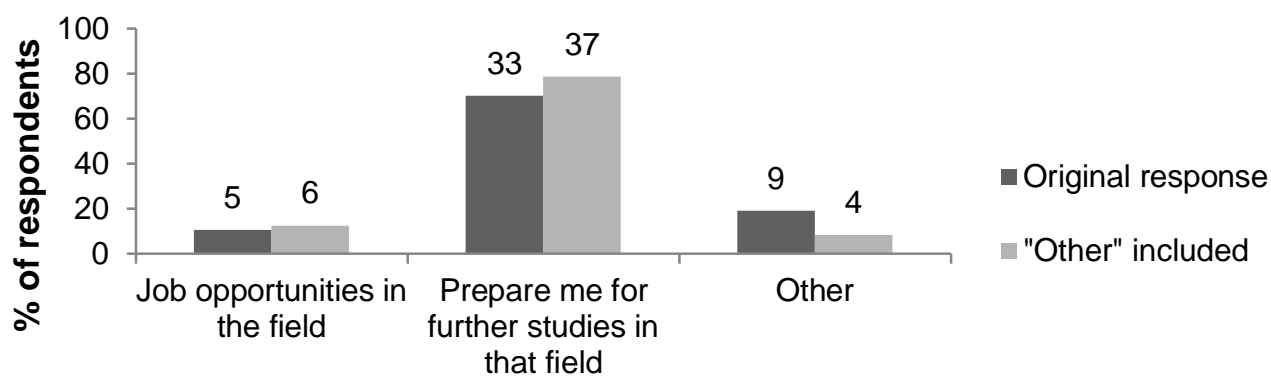

\section{Figure 1: Initial Motivations to Choose the HBP Course}

When focus group participants were asked 'What were your initial motivations to choose the HBP course?', half stated that the degree was a stepping stone to further studies and job opportunities in the field. Comments provided included:

Initially I wanted to pursue a career in physiotherapy and thought this would be a good way to get into the course; however I ended up in a completely different field (Occupational Health and Safety) and couldn't be happier and

I had already decided on a course of study however I did not gain entry from school due to it being competitive, therefore this was my second option and it well prepared me for the second degree I am currently doing which is a graduate entry masters.

Others in the focus group said they chose the course because they had an interest in Human Biology, as indicated in the following responses:

I did a year of the Multidisciplinary Science degree, and one of the units I did (amongst a variety of others, including Scientific Photography, Math and Physics) was Human Biology. Turns out - I loved it! Decided that I wanted to change to this direction and so switched degrees.

Almost all respondents (97.6 per cent) indicated that more education or training was needed after graduating from HBP to find the career they wanted (Table 2).

Table 2: Response to 'Did the HBP Degree give you the Career you Wanted?'

\begin{tabular}{lcc}
\hline HBP degree and satisfactory employment & N & \% of responses \\
\hline BSc HBP degree was enough & 1 & 2.38 \\
More education or training was/is needed & 41 & 97.6 \\
\hline
\end{tabular}

The question 'Which of the following best describes your current situation?' elicited the following responses to predetermined choices (Table 3). Participants were able to choose more than one response.

Table 2: Current Situation

\begin{tabular}{lcl}
\hline Current situation & N & \% of responses \\
\hline Employed full-time & 17 & 25.0 \\
\hline Studying full-time & 16 & 23.5 \\
Employed part-time & 12 & 17.6 \\
Not seeking employment & 8 & 11.8 \\
\hline Not studying & 7 & 10.3 \\
Studying part-time & 4 & 5.90
\end{tabular}

Sornapooman, K. \& Fyfe, G. (2015). Exploring the outcomes of BSc Human Biology graduates and their perceptions of the course. Journal of Teaching and Learning for Graduate Employability, 6 (1), 24-43. 


\begin{tabular}{lcc} 
Unemployed & 2 & 2.90 \\
Seeking employment & 1 & 1.50 \\
Self-employed & 1 & 1.50 \\
\hline Total & $\mathbf{6 8}$ & \\
\hline
\end{tabular}

\section{Further studies}

Of the 42 respondents, 26 stated that they were either currently studying or had completed a subsequent qualification. Of the seven respondents who were not currently studying, six had pursued further studies after graduating HBP. Respondents predominantly attended classes on campus (90\%). Table 4 shows the level and field of qualifications respondents undertook after graduating HBP.

\section{Table 4: Further Study Choices}

\begin{tabular}{|c|c|c|c|}
\hline Level of qualification & $\mathbf{N}$ & $\begin{array}{c}\% \text { of } \\
\text { responses }\end{array}$ & Field \\
\hline Diploma & 4 & 15.3 & $\begin{array}{l}\text { Graduate Diploma Education; Graduate } \\
\text { Diploma Forensic Science }\end{array}$ \\
\hline Masters & 6 & 23 & $\begin{array}{l}\text { Biomedical Engineering; Nursing Practice; } \\
\text { Clinical Psychology; Occupational Therapy; } \\
\text { Medical Imaging Science; Forensic and } \\
\text { Biological Anthropology }\end{array}$ \\
\hline MBBS & 6 & 23 & $\begin{array}{l}\text { Bachelor of Medicine and Bachelor of Surgery } \\
\text { (MBBS); Doctor of Dental Medicine }\end{array}$ \\
\hline TAFE cert IV or below & 2 & 7.69 & $\begin{array}{l}\text { Cert IV in Occupational Health and Safety; Cert } \\
\text { IV in Fitness }\end{array}$ \\
\hline Bachelors & 3 & 11.5 & $\begin{array}{l}\text { Health Safety Environment; } \\
\text { Physiotherapy; Exercise, Sport and } \\
\text { Rehabilitation }\end{array}$ \\
\hline Honours & 3 & 11.5 & $\begin{array}{l}\text { Bachelor of Medical Science (Honours); } \\
\text { Biomedical Science (Honours) }\end{array}$ \\
\hline Other & 2 & 7.69 & Blood Collection (HLTPAT306D) \\
\hline Total & 26 & & \\
\hline
\end{tabular}

Of the respondents who were pursuing or had pursued further studies, 73 per cent stated that the additional qualification was enough to find a career-related job and 15.3 per cent said they would need further study to find a career-related job (Table 5).

\section{Table 5: Outcomes after Further Studies}

\begin{tabular}{lcl}
\hline After completing further study & N (\%) & \% of responses \\
\hline To find a career-related job I will need further study & 4 & 15.3 \\
\hline This qualification is/was enough to find a career-related job & 19 & 73.0 \\
\hline Don't know & 2 & 7.69 \\
\hline I was still not able to find a career related job & 1 & 3.84 \\
\hline Total & $\mathbf{2 6}$ & \\
\hline
\end{tabular}

Only respondents who graduated in 2012 indicated further studies would be required to find a career related job (see Figure 2). Respondents were currently undertaking further studies (full-time or part-time) regardless of the year they graduated from HBP (Figure 3). 


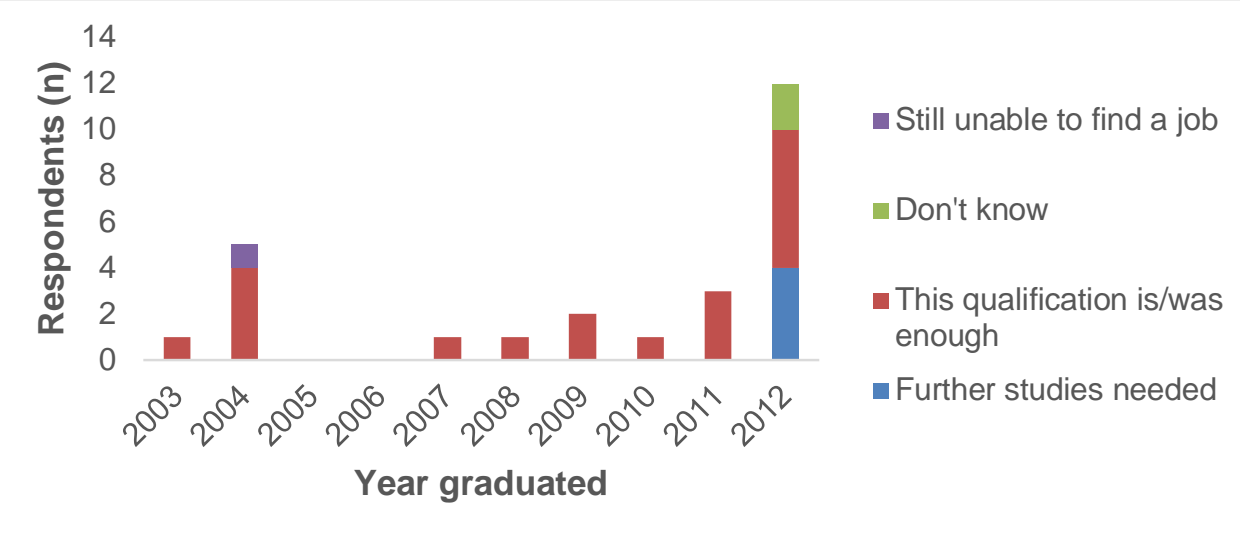

Figure 2: Outcomes after Further Studies across Cohorts

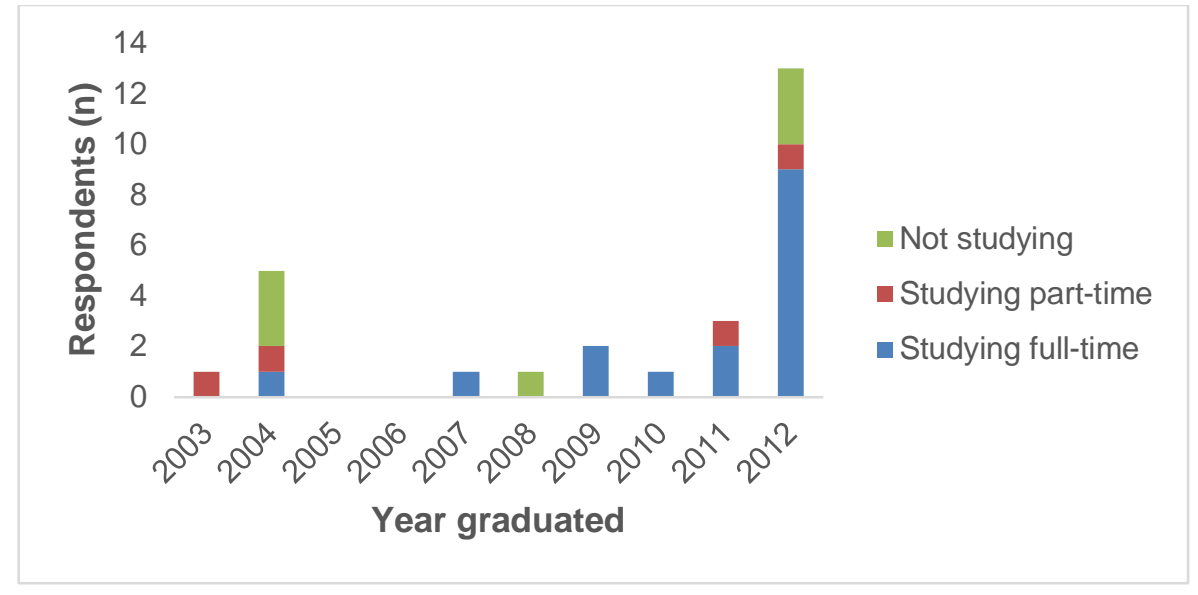

Figure 3: Current Education Status across Cohorts

\section{Employment outcomes}

Thirty eight per cent of respondents had not found a career-related job as they were currently undertaking further studies (Table 6). (This value was obtained after some of the 'Other' responses were allocated into appropriate categories). Some of the responses in the 'Other' category, for example I found a career related job but took longer than expected, and wouldn't describe it as a career so am undertaking further study, contributed to more than one outcome, hence the total with 'other' included 47 responses. The majority of respondents who selected 'Other' clarified that they had found a career, but it was unrelated to the HBP degree.

Table 6: Which of the Following Best Describes what Happened to You after Graduating from HBP?

\begin{tabular}{lcccc}
\hline Outcomes after graduating from HBP & N & $\begin{array}{c}\text { \% of } \\
\text { responses }\end{array}$ & $\begin{array}{c}\mathbf{N} \text { (other } \\
\text { included) }\end{array}$ & $\begin{array}{c}\text { \% of } \\
\text { responses }\end{array}$ \\
\hline $\begin{array}{l}\text { I found a career-related job more quickly than I } \\
\text { had expected to }\end{array}$ & 3 & 7.10 & 6 & 12.7 \\
\hline I found a career-related job after further study & 5 & 11.9 & 8 & 17.0 \\
\hline It took me longer to find a career-related job than & 2 & 4.80 & 3 & 6.30 \\
\hline
\end{tabular}

Sornapooman, K. \& Fyfe, G. (2015). Exploring the outcomes of BSc Human Biology graduates and their perceptions of the course. Journal of Teaching and Learning for Graduate Employability, 6 (1), 24-43. 


\begin{tabular}{lcccc}
\hline $\begin{array}{l}\text { I had expected it to } \\
\begin{array}{l}\text { I still have not found a career-related job as I am } \\
\text { currently undertaking further studies }\end{array}\end{array}$ 15 & 35.7 & 18 & 38.2 \\
$\begin{array}{l}\text { I still have not found a career-related job as I will } \\
\text { need to undertake further studies }\end{array}$ & 6 & 14.3 & 6 & 12.7 \\
\hline I am currently seeking a career-related job & 1 & 2.40 & 1 & 2.12 \\
\hline Other & 10 & 23.8 & 5 & 10.6 \\
\hline Total & 42 & & 47 & \\
\hline
\end{tabular}

Of the 42 respondents, 30 stated that they were currently employed full-time, part-time or self-employed (see Table 3). Some employment questions were not answered by respondents hence total numbers do not equal 30 . Forty per cent of employed respondents worked in the Health Care and Social Assistance area (Table 7) and 55.2 per cent were employed in the private sector. Table 8 shows some of the employment positions of recent and earlier graduate respondents.

\section{Table 7: Main Area of Current Employment}

\begin{tabular}{lcl}
\hline Main area of work & N & \% of responses \\
\hline Retail & 3 & 10.0 \\
\hline Health Care and Social assistance & 12 & 40.0 \\
Education and Training & 3 & 10.0 \\
\hline Occupational Health and Safety & 2 & 6.70 \\
Administrative and Support Services & 2 & 6.70 \\
Research & 2 & 6.70 \\
Other & 6 & 20.0 \\
\hline Total & $\mathbf{3 0}$ & \\
\hline
\end{tabular}

Table 8: Current Employment Positions of Recent and Earlier Graduates

\begin{tabular}{ll}
\hline $\mathbf{2 0 0 3}$ - 2008 graduate positions & $\mathbf{2 0 0 9}$ - 2012 graduate positions \\
\hline Resident Medical Officer & Laboratory/Research Assistant \\
Public Health Officer & Research Associate \\
Senior Scientist (Automated Biochemistry) & Communications Coordinator \\
Injury Management Advisor & Duty Manager \\
Postdoctoral Research Associate & Retail manager \\
Behaviour Support Clinician & Corporate Receptionist \\
Physiotherapist & Service Assistant \\
Manager, Strategic Initiatives (Travel) & Pharmacy Sales Associate \\
Thoroughbred Racehorse Trainer & Academic Tutor \\
Anatomy Technician & Physiotherapist Assistant \\
Health and Safety Manager & Pharmaceutical Representative \\
Anatomy Lecturer & Business Analyst \\
Research Scientist & Dental Assistant \\
Program Consultant (South Sudan) & Public Health Consultant (Bangladesh) \\
Registered Nurse (Darwin) & Rehabilitation Consultant \\
Registered Midwife (Sydney) & Health and Safety Advisor \\
Deck Hand and HSE Officer & Occupational Health Advisor \\
\hline
\end{tabular}


Twenty nine per cent of respondents worked in the outer metropolitan regions and 50 per cent in the inner metropolitan regions of Perth. Four per cent worked in remote areas of Western Australia, 10.7 per cent worked interstate and 7.1 per cent worked overseas. Forty five per cent of respondents stated that previous employment had assisted them to attain their current job. Figure 4 shows the current types of employment (full-time, part-time or selfemployed) across cohorts.

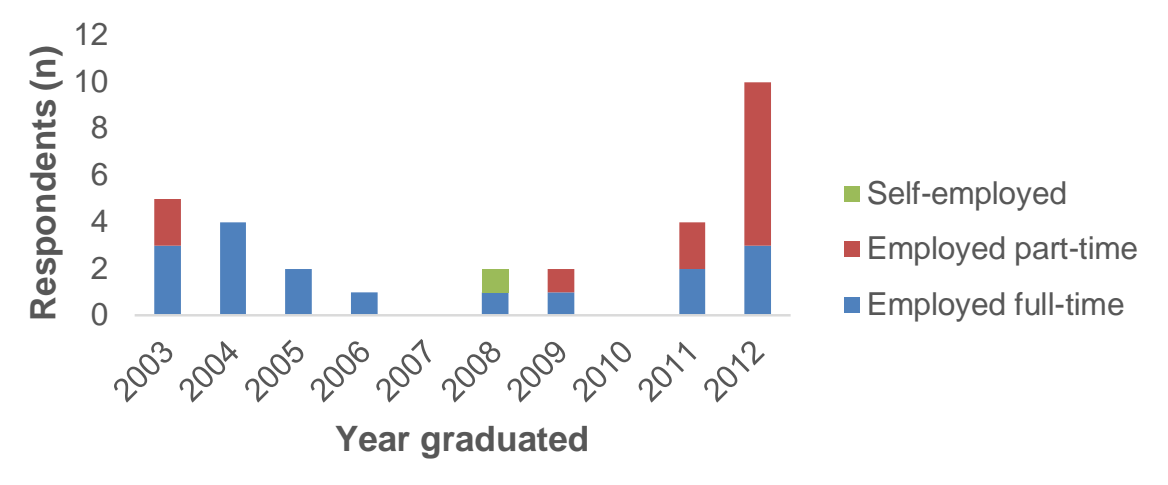

Figure 4: Employment Type across Cohorts

Table 9 shows respondents' views on the match between their current job and the HBP qualification while Figure 5 shows the distribution across cohorts.

\section{Table 9: Match between Current Job and HBP Qualification}

\begin{tabular}{lcl}
\hline Match between current job and HBP qualification & N & \% of responses \\
\hline I am under-qualified for my job & 2 & 7.10 \\
My qualifications match my job & 7 & 25.0 \\
I am overqualified for my job & 11 & 39.3 \\
$\begin{array}{l}\text { Not applicable because I have done further studies to gain my } \\
\text { current job }\end{array}$ & 8 & 28.6 \\
\hline Total & $\mathbf{2 8}$ \\
\hline
\end{tabular}

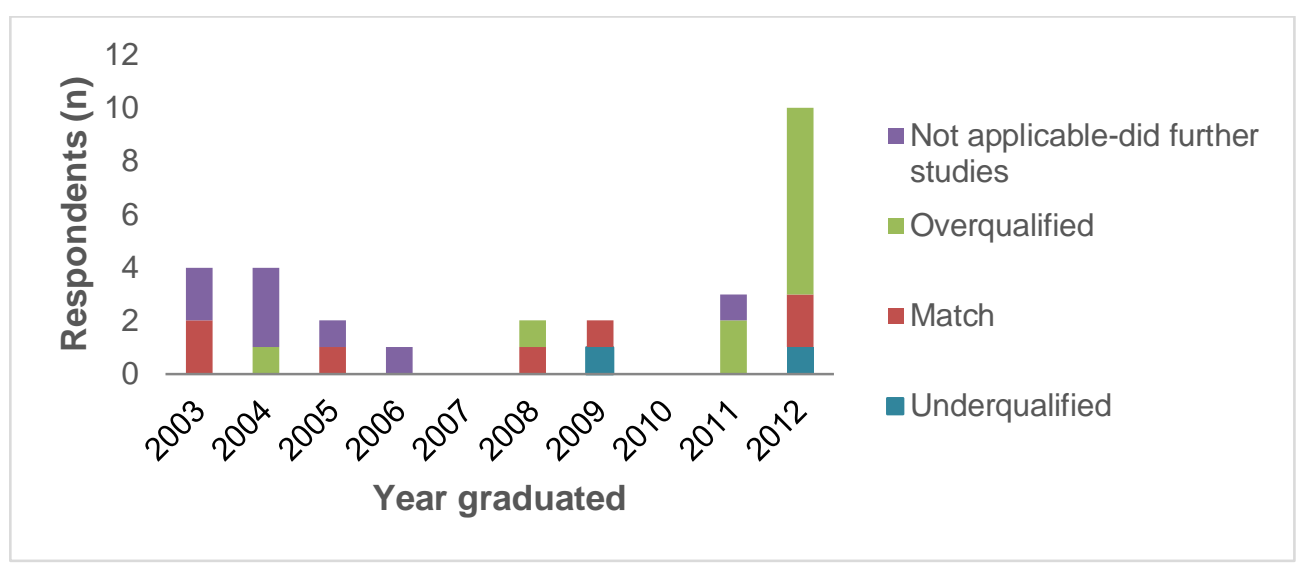

Figure 5: Match between Current Job and HBP Qualification across Cohorts 
On the subject of job satisfaction, thirty five per cent of respondents felt very satisfied with their current job and 6.9 per cent felt very dissatisfied (Table 10). Figure 6 displays level of job satisfaction across cohorts.

\section{Table 10: Satisfaction with Current Job}

\begin{tabular}{lcl}
\hline Satisfaction with current job & N & \% of responses \\
\hline Very satisfied & 10 & 34.5 \\
Somewhat satisfied & 11 & 37.9 \\
Neutral & 5 & 17.2 \\
Dissatisfied & 1 & 3.40 \\
Very dissatisfied & 2 & 6.90 \\
\hline Total & $\mathbf{2 9}$ & \\
\hline
\end{tabular}

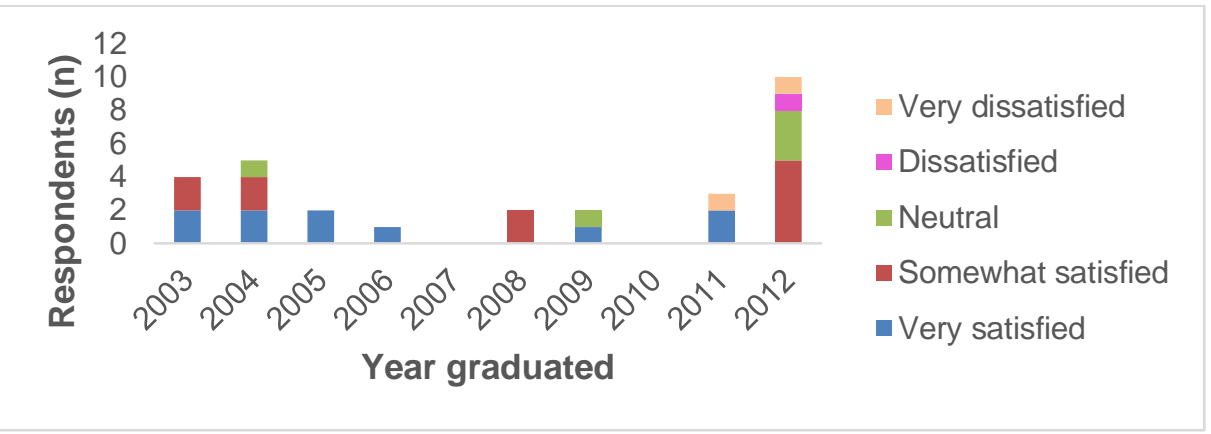

Figure 6: Satisfaction with Current Job across Cohorts

When considering the future of their job, just over forty one per cent of respondents said that their current job was a career, 27.6 per cent said it was a stepping stone to a career and 31 per cent said that it was just a job to get them by (Table 11). Figure 7 displays the distribution across the cohorts.

Table 11: Outlook of Current Job

\begin{tabular}{lcl}
\hline Do you think of your current job as: & N & \% of responses \\
\hline A career & 12 & 41.4 \\
A stepping stone & 8 & 27.6 \\
Just a job (to get you by) & 9 & 31.0 \\
\hline Total & $\mathbf{2 9}$ & \\
\hline
\end{tabular}

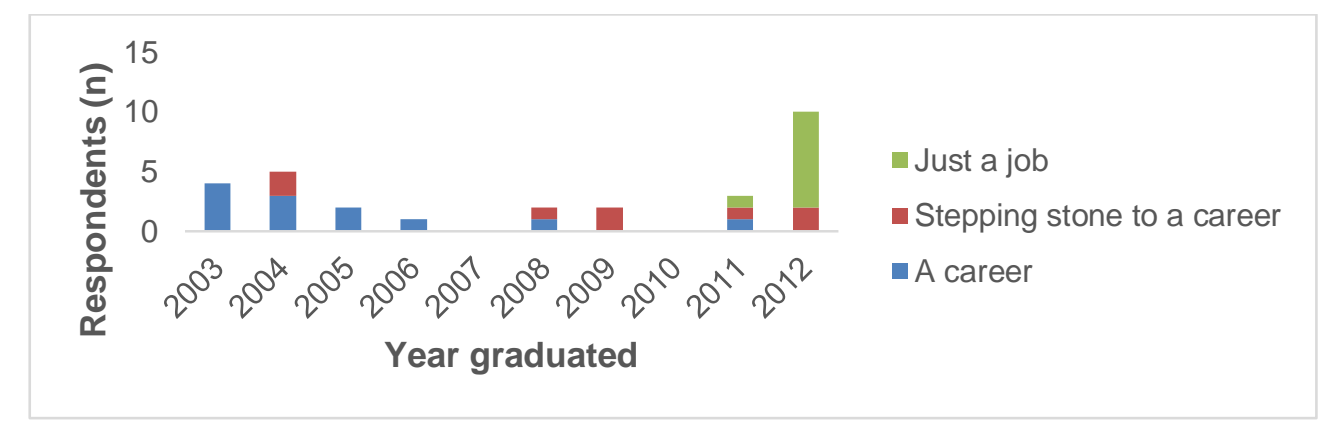

Figure 7: Outlook of Current Job across Cohorts

Sornapooman, K. \& Fyfe, G. (2015). Exploring the outcomes of BSc Human Biology graduates and their perceptions of the course. Journal of Teaching and Learning for Graduate Employability, 6 (1), 24-43. 


\section{Perceptions of the HBP degree course}

Graduates were invited to provide open-ended responses to four items (see page 27) regarding their perceptions of the most useful and influential aspects of the course. For convenience, these are referred to as Influential Aspects, External Factors, Useful Aspects and Needs Improvement. Of the 42 respondents, 35 provided comments on Influential Aspects, 34 on External Factors, 36 on Useful Aspects and 35 on Needs Improvement. Coded focus group transcripts were combined with these four categories, therefore increasing the weight of opinion of a few respondents.

Respondents' cited specific units in the course as the most Influential Aspects. Physiology and anatomy units were commonly mentioned. Many respondents also identified diversity of the units offered as the most Influential Aspect. Units that were offered covered broad aspects of human biology such as physiology, anatomy, neuroscience, reproduction and human evolution and gave graduates the opportunity to determine what interests them. The following comments were offered:

The broad aspects of the degree (ranging from basic physiology, human evolution, reproduction and anatomy) helped me decide on the specific career path/interest in which I plan to undergo further study into and potentially get a job in.

Because the Human Biology degree was very broad in its contents, it gave me a taste of a number of different areas and aspects which were of interest. A particular area was that of Psychology and Neuroscience which will be my focus next year after I finish travelling. In a nutshell the diversity of the degree would be its greatest aspect.

Respondents also made reference to using the degree as a stepping stone for further studies as they had already decided on future plans. Some indicated that there were no influential aspects in the course as they were still unsure about future plans. Others stated an overall interest in learning about the human body (Figure 8).

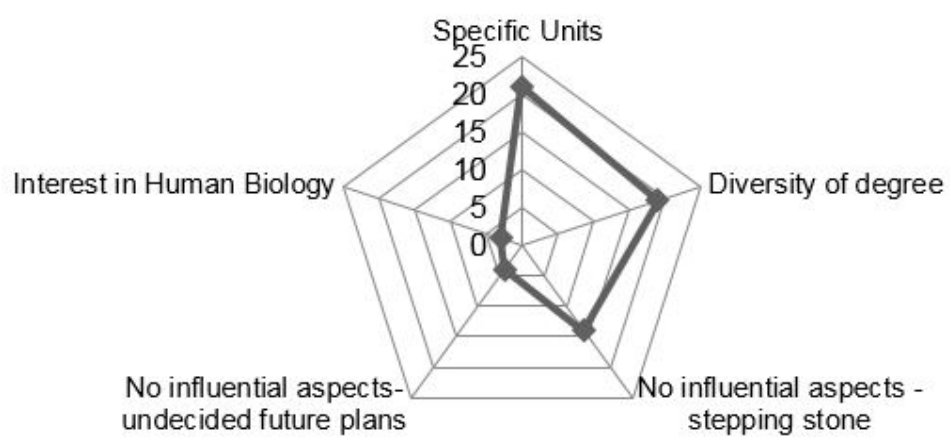

Figure 8: Influential Aspects of the Course that Assisted with Future Decisions

Respondents identified personal interest and experiences as the main 'External Factors' that influenced further study or career decisions with comments such as:

Various factors have influenced my choices. Having seen a significant amount of people suffer from mental disorders was one of the key factors which perked my interested in the mind.

University life, networking and socialising as well as work experience were also frequently mentioned as evidenced in the following comments: 
I have mainly made my decisions for work and study based on casual conversations with friends from school and university. I never saw a career advisor or attended a university open day.

After I completed the degree I was involved in research with plastic and reconstructive surgeons at $\mathrm{PMH}$, which inspired me to follow the medical career path.

The other somewhat less influential 'External Factor' mentioned was career information sessions (Figure 9).

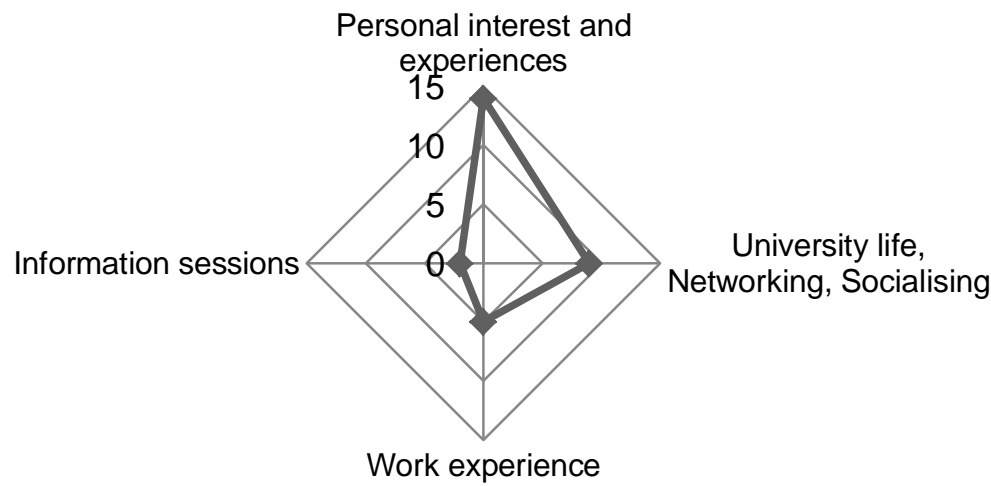

Figure 9: Influential Aspects External to the Course that Assisted with Future Decisions

The two main 'Useful Aspects' included specific units and a good foundation for further studies as seen below:

The grounds/basis created by studying physiology and anatomy in depth helped to prepare me for more in depth units of study completed in the final year of the degree.

I feel that the Human Biology degree gives a very good introduction to a wide variety of subjects that are then useful for several other areas of study and then career.

Many respondents also mentioned certain skills and attributes gained during the course as the most useful aspects, including problem solving skills, critical analysis, independent learning, scientific thinking and team-work skills. Some indicated the course experience, environment and friendships made were the most Useful Aspects, while others said they gained confidence throughout the course (Figure 10).

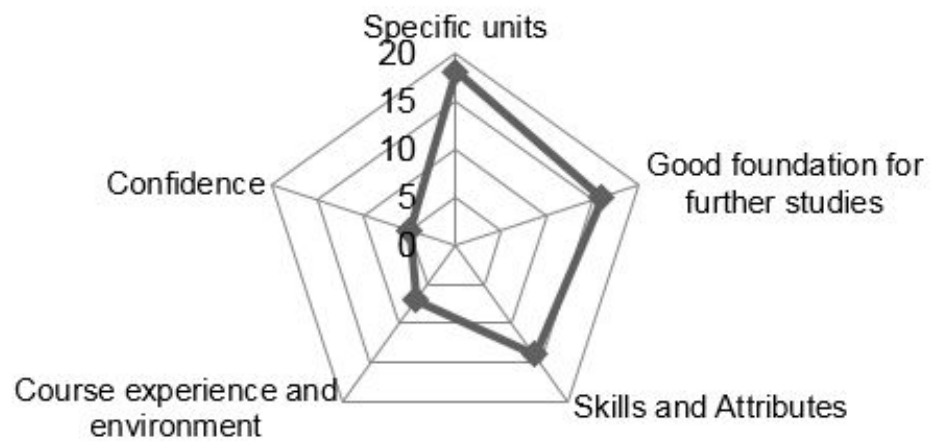

Sornapooman, K. \& Fyfe, G. (2015). Exploring the outcomes of BSc Human Biology graduates and their perceptions of the course. Journal of Teaching and Learning for Graduate Employability, 6 (1), 24-43. 


\section{Figure 10: Most Useful Aspects of the Course Since Graduating}

In terms of areas for improvement, respondents felt they needed more information on job prospects as seen in the comment below:

Provide more information about career paths that can be taken after human biology: day in the life of a doctor, physio, occupational health etc.

Many also mentioned the need for work placement during the course as well as specific units that would be useful for further studies. Respondents also felt that the HBP degree course alone did not provide satisfactory employment. A few mentioned that the degree was not recognised by employers (Figure 11).

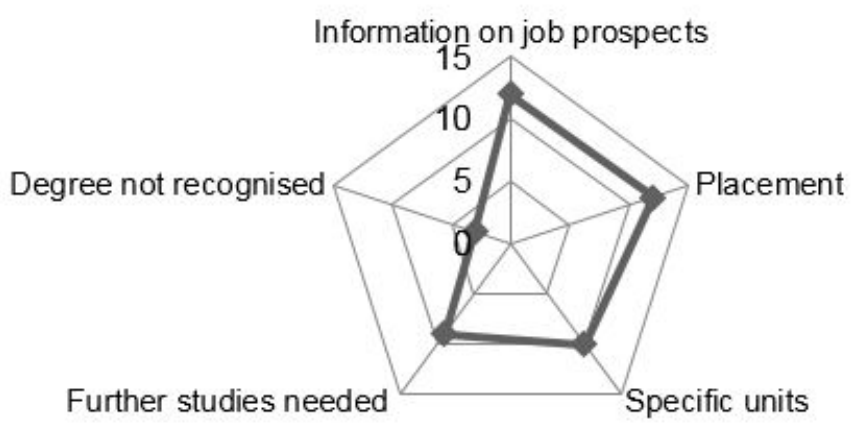

Figure 11: Areas of the Course that Need Improvement

\section{Discussion}

Human Biology Preclinical graduates fell into four graduate profiles, based on all qualitative responses.

The largest group consisted of graduates who had a set career pathway in mind and used the HBP course successfully as a stepping stone to further studies. Graduates who fell into this category were those that did not meet the Tertiary Entrance Rank (TER) scores to get into their preferred course. Others did not feel ready to undertake a challenging course and chose to study HBP to gain confidence, knowledge and skills.

The second most common profile was graduates who chose to study HBP with a set career pathway in mind but internal and or/external factors relating to the course had altered their plans.

The third profile consisted of graduates who chose to study HBP with undecided future plans and internal and/or external factors had helped them make decisions. Specific units and the diversity of the course were considered the most influential aspects. This is not surprising as the course is non-professionally orientated and therefore the units were designed to be broad and do not lead to a particular career pathway. Findings also suggest that the most influential aspect external to the course was personal interest and experiences followed by university life, networking and socializing, and work experience. Conversations with university staff and friends helped graduates make decisions on further education options and career pathways. Employment while studying HBP or after completing the degree had also influenced graduates future decisions.

The least common graduate profile was that of students who had not made a decision regarding their future plans when choosing to study the HBP course. They indicated that 
there were no influential aspects and unsurprisingly still had undecided future plans after graduating.

The findings show that most respondents believed that the diversity and breadth of the degree was the most useful aspect of the course as it provided a good introduction to a wide variety of subjects that are also useful as a foundation for other areas of both study and careers. Specific units in the course were also mentioned as the most useful aspect, although perceptions of these varied depending on the chosen pathways of respondents.

Graduates from earlier cohorts identified information on possible job prospects as the key aspect requiring improvement. In recent years, such measures have been taken to provide students with information on job opportunities. Respondents also indicated the need for workplace experience during the course. Although studies have shown that work placement is key to enhanced employability, it is challenging to establish work place experience for students who major in a non-professional course as there is no prescribed career. Interestingly, the 2012 Graduate Outlook Survey [GOS] revealed that 'work experience' was one of the least frequently nominated selection criterion when employers were asked what they considered to be most important when evaluating applicants. However, since the current findings have established the profiles of graduates, placement and work experience could be tailored to fit particular graduate profiles.

\section{Graduates doing further studies}

This study has shown that the majority of respondents chose to study HBP to prepare them for further studies in the field. According to GCA (2013d), 15.3 in every 100 respondents across all degree levels continued on to full-time study, a figure which has continued to increase. A key factor for the high number of HBP graduates undertaking further study may be the difficulty in finding full-time employment due to the science-based labour market demanding postgraduate degrees of potential employees (Carroll \& Tani, 2013). We know that some undergraduate degrees require at least some further study to gain access to employment in the field (GCA, 2013d) and although a bachelor's degree can successfully be used to gain employment, a higher level of qualification would not only increase the chances of gaining full-time employment but also achieve a higher or more specific position. Furthermore, the HBP degree is not professionally orientated allowing flexibility in career choice and providing a stepping stone to further studies in the field instead of leading to a specific career. The downside of the non-professional orientation is that most graduates are likely to need further education to improve their employment prospects. Psychology and other non-specific health-related degrees all have high numbers of graduates undertaking further studies (GCA, 2013d). On the other hand, the extent of further study is particularly limited for graduates from degrees with a professional orientation such as nursing and engineering (GCA, 2013d). Employers considered academic qualifications as one of the most important aspects they look for in a graduate's curriculum vitae (GCA, 2013b: GOS 2012). Furthermore, employers increasingly seek graduates with the potential to lead workplace change and innovation (Lowden, Hall, Elliot \& Lewin, 2011) and those with a preprofessional identity (Purcell, Elias, Atfield, Behle, Ellison \& Luchinskaya, 2013).

It is not surprising that a high number of respondents chose to undertake further studies. Levels of further education ranged from a TAFE certificate to a masters or doctoral degree. This is similar to previous studies which show that a significant number of graduates pursue some kind of further education after graduating. Within the first few years of graduating, there is an active involvement of graduates advancing their skills and knowledge in both higher education and vocational programs (ACER, 2008). A bachelor degree is the fundamental basis needed to progress in higher education, rather than the only qualification that will satisfy their career goals. This is particularly the case for science graduates. Carroll and Tani (2013) reported that science graduates had a much higher chance of working in employment related to their field of study if they held a postgraduate qualification, (68 per cent postgraduate and 43 per cent bachelor's degree in a degree related job). This shows a

Sornapooman, K. \& Fyfe, G. (2015). Exploring the outcomes of BSc Human Biology graduates and their perceptions of the course. Journal of Teaching and Learning for Graduate Employability, 6 (1), 24-43. 
significant postgraduate advantage to those in science-related degrees (Carroll \& Tani, 2013).

\section{Employment outcomes}

Respondents were currently undertaking further studies (full-time or part-time), regardless of the year they graduated from HBP. Although it is more likely for generic degree graduates to require further study to direct their vocational goals, this also suggests that education is a lifetime progression and graduates may actively seek further education to enhance their knowledge and skills in the years following graduation. This finding is consistent with previous studies (Purcell, Elias, Davies \& Wilton, 2005; Bradburn, Nevill \& Forrest, 2006; Allen \& van der Velden, 2008; Cummings, 1998). Pursuing further studies may also be due to changes in ambitions and outlooks in relation to the kind of job and wage after being in the employment field for several years. This matches several long-term studies (Heazlewood, Pymm \& Sanders, 2006; Goyal \& Weiler, 2006; Licciardi \& Miller, 2004). Furthermore, employers occasionally support new graduate employees to participate in external training and development to further their knowledge and skills (GCA, 2013b: GOS 2012, Bierbaum, 2007)).

Part-time employment was more common in recent graduates (2009-2012) and most respondents from earlier cohorts were in full-time employment. Most respondents were appropriately placed in the work force to match their qualifications and skills four years after graduating. This matches respondents' views on their current job. Others (Coates \& Edwards, 2009) have reported appropriate placement in the workforce around five years after graduating, across a broader range of undergraduate degrees. Recent graduates in part-time employment were more likely to state that they were overqualified and dissatisfied with their current job and indicated that their current employment was just a job to get them by, while earlier graduates were satisfied with their current jobs and identified their job as a career. This is not surprising as professionally-orientated courses may actively place students in employment through fieldwork placements, while non-professional graduates are involved in further studies to achieve satisfactory employment. These findings are consistent with previous studies (GCA, 2013a: BGS 2012). Further, recent graduates may be more likely to stay in un-related part-time employment while they are in the process of securing employment relative to their degree (Carroll \& Tani, 2013). With the drive to uncap university places, and national targets to increase the number of Australians with Bachelor degrees to 40 per cent of those aged 25-24 by the year 2025 (Sellar, 2013), the already congested labour markets will attract more potential applicants than there is demand for (Brown, Lauder \& Ashton, 2011).

Respondents who graduated in earlier years were more likely to hold higher positions, attained after further qualifications. Respondents had on average two to three employers within four years of graduating from HBP. Graduates potentially made transitions to managerial positions once they had accumulated the necessary experience and skills which is similar to findings from the 2012 BGS report.

\section{Limitations of the study: Methodological considerations}

Participants were recruited via personal/university emails and/or social media Facebook (FB). This enabled a large number of individuals to be contacted in a cost-effective manner within a short period of time and also helped to capture hard-to-reach participants, such as those who graduated 10 years ago. However, it may have also contributed to the low response rate in the study. For example, the non-response to the private FB messages could be due to the FB system itself. When graduates were privately messaged on FB the following notification was received: 'You aren't connected to [participant name] on Facebook, so your message would normally get filtered from their inbox to his/her Other folder'. The non-response to university emails could be due to graduates less frequently checking their

Sornapooman, K. \& Fyfe, G. (2015). Exploring the outcomes of BSc Human Biology graduates and their perceptions of the course. Journal of Teaching and Learning for Graduate Employability, 6 (1), 24-43. 
university emails upon graduation. Furthermore, Curtin University student emails are deactivated one year after students graduate.

The lack of key contacts in several cohorts resulted in a poor response rate. The importance of a key contact to improve response rates can be seen in the 2004 HBP cohort. Graduates were more likely to participate in the survey when asked to participate by someone they knew instead of by an unknown investigator.

Conflicting results whereby only 26 of the 42 respondents that indicated they were either currently studying or had completed their qualification is primarily due to poor survey design, in particular the question 'Which of the following best describes your current situation'. Respondents were required to select three of the possible seven choices available, however several respondents only selected one choice and because of skip logic, specific questions such as those asking about further studies were not displayed. A 'force response validation' should have been used to ensure all relevant parts of the question were answered before allowing the respondent to continue. The broadness of the open-ended question on useful aspects of the course caused a lack of in-depth responses. Consequently, it was difficult to investigate specific generic attributes and skills attained during the course such as writing and communication skills, solving complex, real-world problems and thinking critically.

Qualitative information from the focus groups helped to increase the quality of the survey questions and range of variables. The face-to-face method had high interaction between participants, and provided rich, in-depth data. However, participation rates were low because travelling to the venue was inconvenient and finding a time suitable for all participants was difficult. More participants took part in the online method as it was convenient and gave participants the freedom to manage their own time deciding when to contribute to the discussion. The main limitation with the online method was the loss of group interaction and the need for participants to write answers resulted in a lack of depth. For future studies, telephone interviews could be a more productive approach (Sturges \& Hanrahan, 2004) as it allows more iterative interaction compared to online methods. Qualitative studies have found response rates and participation increase when using telephone interviews as they accommodate participants who have difficulty finding a suitable time (Fenig, Levav, Kohn \& Yelin, 1993).

The authors acknowledge that an employment bias exists in the results of this study due to the geographical isolation of the region (Western Australia) and the professional boundaries of the possible HBP course graduate outcomes. A caveat should also be placed on the selfreported nature of the data in this study.

\section{Conclusion}

This study provided an insight into HBP graduate destinations and outcomes over the last 10 years. The sample was small but key findings were:

Most HBP graduates were involved in further studies upon graduation before seeking a career-related job. Most settled into a career four years after graduating from HBP. The sample in this study assorted into four profiles, based on their initial goals, goals formed during their HBP degree and those still without goals at graduation. Further, most believed that while the degree itself did not provide satisfactory employment, it did provide the fundamentals required for further studies because it was diverse and it developed the confidence to pursue future goals. The main areas for improvement included career advice and the need for work place experience during the course.

A study such as this which focuses on the usefulness and impact of the course on graduates' work lives, has the potential to inform the curriculum review process of the HBP course. It also documents the achievements of HBP graduates, giving prospective students insight into where the degree may lead them and assisting current students in developing future career goals. This research may assist universities in providing useful information for

Sornapooman, K. \& Fyfe, G. (2015). Exploring the outcomes of BSc Human Biology graduates and their perceptions of the course. Journal of Teaching and Learning for Graduate Employability, 6 (1), 24-43. 
prospective students in course handbooks and orientation sessions for generic undergraduate degrees. Prospective students should be aware that non-professional courses do not necessarily result in a professional qualification and lead to a direct career without further postgraduate training and education. Potential students who need a stepping stone degree to achieve their desirable course and career, and those who are unsure of their professional direction, would benefit most from non-professional orientated courses. In addition, students studying a generic course should be provided with information on job prospects with the degree after the first year.

Further research using a larger sample is necessary to determine the extent to which the views expressed by each cohort in this study are representative. Attaining more key contacts in each cohort and making the online survey available for a longer period of time could improve the response rate. Now that there is long-term information on HBP graduate destinations, future studies into useful attributes and capabilities attained throughout the course and employer requirements will be essential. 


\section{References}

Allen, J. \& van der Velden, R. (2008). The flexible professional in the knowledge society: General results of the REFLEX project. Maastricht: Research Centre for Education and the Labour Market.

Australian Council for Educational Research (2008). The 2008 graduate pathways survey: Graduates' education and employment outcomes five years after completion of a bachelor's degree at an Australian university. Camberwell: ACER.

Barrie, S. C. (2012). A research-based approach to generic graduate attributes policy. Higher Education Research and Development, 31(1), 79-92.

Bierbaum, R. (2007). University of South Australia graduate qualities and learning outcomes. Employer feedback discussion paper. University of South Australia: Carrick Institution for Learning and Teaching in Higher Education.

Bradburn, E. M., Nevill, S., \& Forrest, C. E. (2006). Where are they now? A description of 1992-93 Bachelor's Degree recipients 10 years later. Washington DC: U.S.

Britt, F. A. \& Weingart, S. J. (2005). Using focus groups to assess student needs. Library Review, 54(9), 524-530.

Bowden, J., Hart, G., King, B., Trigwell, K., \& Watts, O. (2000). Generic capabilities of ATN university graduates. Canberra: Australian Government Department of Education, Training and Youth Affairs.

Brown, P., Lauder, H., \& Ashton, D. (2011). The global auction: The broken promises of education, jobs and incomes. UK: Oxford University Press.

Carroll, D. \& Tani, M. (2013). Over-education of recent higher education graduates: New Australian panel evidence. Economics of Education Review, 32(2013), 207-218.

Coates, H. (2005). The value of student engagement for higher education quality assurance. Quality in Higher Education, 11(1), 25-36.

Coates, H. \& Edwards, D. (2009). The 2008 Graduate Pathways Survey: Graduates' education and employment outcomes five years after completion of a bachelor degree at an Australian university. Melbourne: Australian Council for Educational Research. Retrieved from http://research.acer.edu.au/cgi/viewcontent.cgi?article=10 11\&context=higher_education

Covell, C. L., Sidani, S., \& Ritchie, J. A. (2012). Does the sequence of data collection influence participants' responses to closed and open-ended questions? A methodological study. International Journal of Nursing Studies, 49(6), 664-671.

Cummings, R. (1998). How should we assess and report student generic attributes? Paper presented at the 7th Annual Teaching and Learning Forum. Australia: Nedlands.

Fenig, S., Levav, I., Kohn, R., \& Yelin, N. (1993). Telephone vs face-to-face interviewing in a community psychiatric survey. American Journal of Public Health, 83(6), 896-898.

Goyal, K. \& Weiler, B. (2006). University education and employment outcomes: Brand matters. Monash Business Review, 2(3), 1-6.

Grace, D., Weaven, S., Bodey, K., Ross, M., \& Weaven, K. (2012). Putting student evaluations into perspective: The Course Experience Quality and Satisfaction Model (CEQS). Studies in Education Evaluation, 38(2), 35-43.

Graduate Careers Australia. (2013a). Beyond Graduation Survey 2012 (BGS). Melbourne: GCA.

Graduate Careers Australia. (2013b). Graduate Outlook Survey 2012 (GOS). Retrieved from http://www.graduatecareers.com.au/wpcontent/uploads/2011/12/GOS12_Report_FINAL2.pdf 
Graduate Careers Australia. (2013c). Australian Graduate Survey 2011. The Report of the Conduct of the 2011 Australian Graduate Survey. Retrieved from http://www.graduatecareers.com.au/research/researchreports/

Graduate Careers Australia (2013d). Graduate destinations 2012: A report on the work and study outcomes of recent higher education graduates. Melbourne: GCA.

Graduate Destination Report. (2011). Faculty of Health Sciences. Graduate Employment 2011 (pp. 468-590). Careers Centre: GCA.

Heazlewood, J., Pymm, B., \& Sanders, R. (2006). Where are they now? A survey of Charles Sturt University library and information management graduates. Australian Library Journal, 55(4), 330-342.

Li, I. W. \& Miller, P. W. (2013). The absorption of recent graduates into the Australian labour market: Variations by university attended and field of study. Australian Economic Review, 46(1), 14-30.

Licciardi, R. \& Miller, S. (2004). Management student perceptions of professional career development education. Victoria University of Technology: Footscray.

Lowden, K., Hall, S., Elliot, D., \& Lewin, J. (2011). Employers' perceptions of the employability skills of new graduates. London: Edge Foundation.

McInnis, C., Griffin, P., James, R., \& Coates, H. (2001). Development of the Course Experience Questionnaire (CEQ): Evaluations and Investigations Programme. Higher Education Division, Department of Education, Training and Youth Affairs.

Nair, S. \& Mertova, P. (2009). Conducting a graduate employer survey: A Monash University experience. Quality Assurance in Education, 17(2), 191-203.

Oliver, B., Whelan, B., Hunt, L., \& Hammer, S. (2011). Accounting graduates and the capabilities that count: Perceptions of graduates, employers and accounting academics in four Australian universities. Journal of Teaching and Learning for Graduate Employability, 2(1), 2-27.

Purcell, K., Elias, P., Atfield, G., Behle, H., Ellison, R., \& Luchinskaya, D. (2013). Transitions into employment, further study and other outcomes. Warwick: Warwick Institute of Employment Research.

Purcell, K., Elias, P., Davies, R., \& Wilton, N. (2005). The class of '99: A study of the early labour market experiences of recent graduates. Warwick:Warwick Institute for Employment Research.

Schomburg, H. (2007). The professional success of higher education graduates. European Journal of Education, 42(1), 35-47.

Sellar, S. (2013) Equity, markets and the politics of aspiration in higher education. Discourse: Studies in the Cultural Politics of Education, 34(2), 245-258.

Shah, C., Cooper, L., \& Burke, G. (2007). Industry demand for higher education graduates in Victoria. Melbourne: Office of Training and Tertiary Education, Department of Innovation, Industry and Regional Development.

Sturges, J. E. \& Hanrahan, K. J. (2004). Comparing telephone and face-to-face qalitative interviewing: A research note. SAGE Journals, 4(1), 107-118.

Tucker, B., Pegden, J., \& Yorke, J. (2012). Outcomes and evaluations: Is there a relationship between indicators of student success and student evaluations of learning? In $\mathrm{N}$. Brown, S. M. Jones \& A. Adam (Eds.), Research and Development in Higher Education: Connections in Higher Education (Vol. 35, pp. 326-339).

Yilmaz, K. (2013). Comparison of quantitative and qualitative research traditions: Epistemological, theoretical, and methodological differences. European Journal of Education, 48(2), 311-325. 